\title{
Factors Defining Value and Direction of Thermal Drop Between Mine Shafts and Impact of General Mine Natural Draft on Ventilation Process of Underground Mining Companies
}

\author{
Alexandr V. Nikolaev \\ Perm National Research Polytechnic University (PNRPU) \\ Perm, Russia, Komsomol'skiy Ave. 29 \\ e-mail: nikolaev0811@mail.ru
}

Anton A. Kamenskikh

Mining Institute of the Ural Branch of the Russian Academy of Sciences (MI UB RAS)

Perm, Russia, Sibirskaya St. 78-A

e-mail: anton.kamenskikh@mi-perm.ru

Viktor A. Nikolaev

Perm National Research Polytechnic University (PNRPU)

Perm, Russia, Komsomol'skiy Ave. 29

e-mail: eagp@mail.ru

\author{
Nikolay I. Alymenko \\ Mining Institute of the Ural Branch of the Russian Academy \\ of Sciences (MI UB RAS) \\ Perm, Russia, Sibirskaya St. 78-A \\ e-mail: nik.alymenko@yandex.ru
}

Daniil N. Alymenko

Joint stock company "VNII Galurgii" ("VNII Galurgii” JSC)

Perm, Russia, Sibirskaya St. 94

e-mail: gallurgy@mail.ru

Alexandr I. Petrov

Mining Institute of the Ural Branch of the Russian Academy of Sciences (MI UB RAS)

Perm, Russia, Sibirskaya St. 78-A

e-mail: alex231287@yandex.ru

volume, required for ventilation of an underground mining company, depends on the quantity of mining areas, the quantity of mine workers in the mine, gas content of the workings etc. Depending on these parameters, a required MMF capacity is specified.

However volume flow of the supplied air changes continuously because the ventilation process is being influenced by the general mine natural draft (general mine thermal drop) arising between the mine shafts as a result of the difference of air density in it. In case if a direction of the general mine natural draft coincides with the specified (required) direction of air circulation in the mine, the draught is specified as a positive general mine natural draft (general mine thermal drop). If the general mine natural draft is directed opposite the air flow circulation, this phenomenon prevents from the normal ventilation mode - a negative general mine natural draft [1-6].

By certain conditions the negative general mine natural draft can achieve a value by which MMF will not be able to provide supply of the required air volume into the mine. Such a situation is unacceptable in terms of safety. In this case it is necessary to switch the fan operation to higher-pressure area which leads to the increase of its power consumption (Figure $1, a)$. It is unreasonable to hold a high MMF capacity 


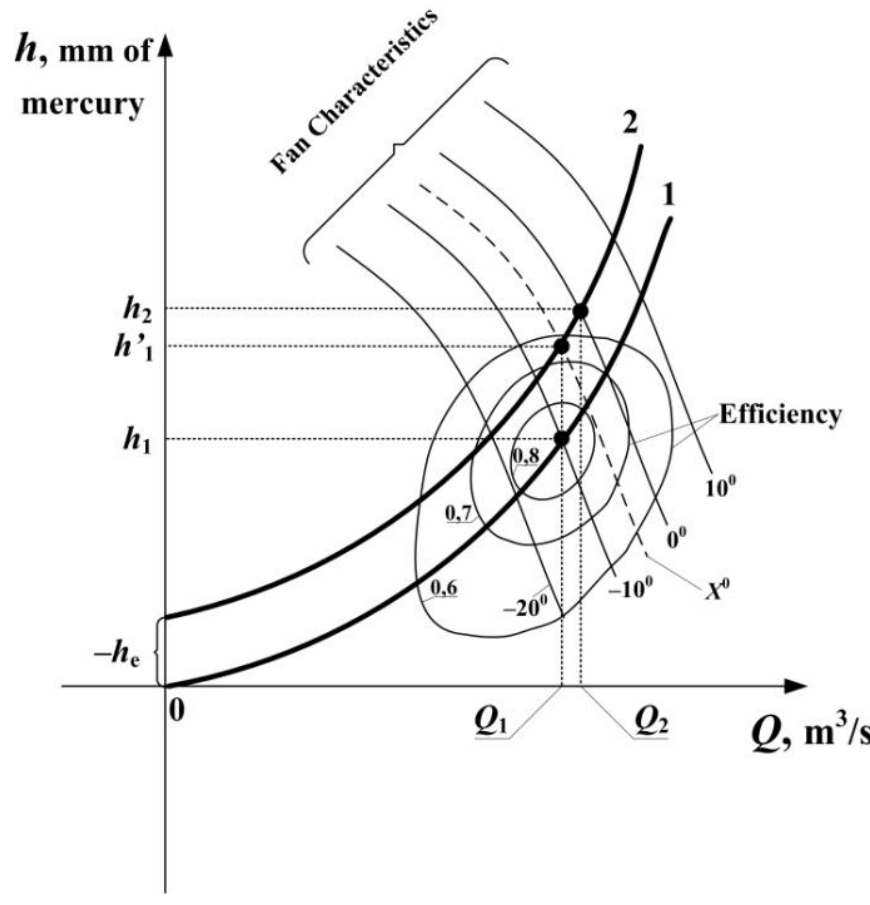

a)

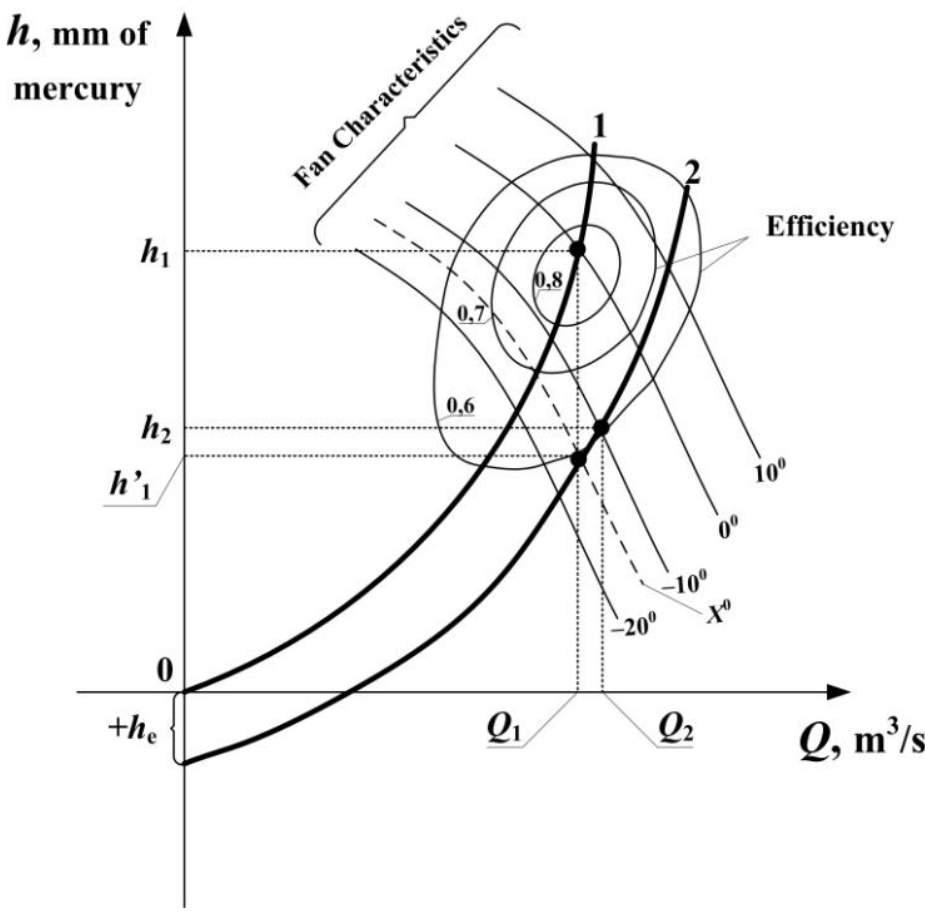

b)

Fig. 1. The effect of natural draft on the operation of the MMF:

$a$-negative general mine natural draft; $b$ - positive general mine natural draft

By

action of the positive general mine natural draft on the contrary, the mine will be supplied with larger air volume, so fan operation can be switched to lower-pressure area, i.e. the consumed power can be decreased (Figure 1,b).

The above-mentioned implies that a definition of the value of the general mine natural draft, its action direction as well as factors which influence its value, is a critical task to settle out the issue of safety and energy efficiency of the ventilation process in underground mining companies.

\section{RESULTS AND DISCUSSION}

Reasons of air circulation caused by convective heat transfer are known quite long ago. However, there are different opinions by description of the impact degree of natural draft (thermal drop) on the ventilation process in underground mining companies. For example, the paper [7] specifies a supposition that natural draft between the shafts can arise only if they are forcibly supplied with air, i.e. the draught alone is impossible without additional draught sources.

A supposition is often said that the mine depth and the value of the general mine natural draft are interrelated. The papers $[8,9]$ suggest that due to the increase of air temperature with the increase of the shaft depth, the natural draft also rises, i.e. the deeper the mine, the higher the draught. According to the paper [7], the natural draft has no special impact on the ventilation process because great depth results in the high value of the shaft air-flow resistance. In this case, it is supposed that the considerable natural draft between the mine shafts is compensated due to their high air-flow resistance.

To identify actual factors which influence the value of the general mine natural draft between the shafts and accordingly to analyze its impact degree on the ventilation process, measurements by MMF shutdown have been performed in BKPRU-2 mine («Uralkali»PJSC»).

Table 1 specifies the measurements results where $t_{\mathrm{H}}, t_{1}$ $, t_{2}, t_{3}$ are temperatures accordingly of the outer air, air in shafts №1, 2 (air inlet shafts) and 3 (ventilation shaft), ${ }^{\circ} \mathrm{C} ; P_{\mathrm{a}}$ is airpressure, mm of mercury; $P_{1}, P_{2}, P_{3}$ is pressure in the shaft bottom accordingly of shafts № 1, 2, 3, mm of mercury; $Q_{1}, Q_{2}, Q_{3}$ is volume air flow accordingly in air inlet shafts № 1 , 2 and in ventilation shaft № 3 .

The MMF shutdown was carried out at 22.00 (line 1, table 1).

As is seen from the table, at this moment the shafts were supplied with the air volume sufficient for the normal operation mode of the mine. After 20 minutes, the volume air flow supplied to the underground mining workings decreased approximately two times, and after another 20 minutes changed its direction to the contrary. 
The air circulation was continuous for 6 hours, i.e. all the time the ventilation was produced due to the general mine natural draught.

Based on the performed measurements, the authors of this paper have supposed as follows:
1. The general mine natural draft $\left(h_{\mathrm{e}}\right)$, due to which ventilation was produced by the MMF shutdown, and which influences the ventilation process by its operation, depends on the mutual action of thermal drop between each pair of the interconnected shafts (Figure 2).

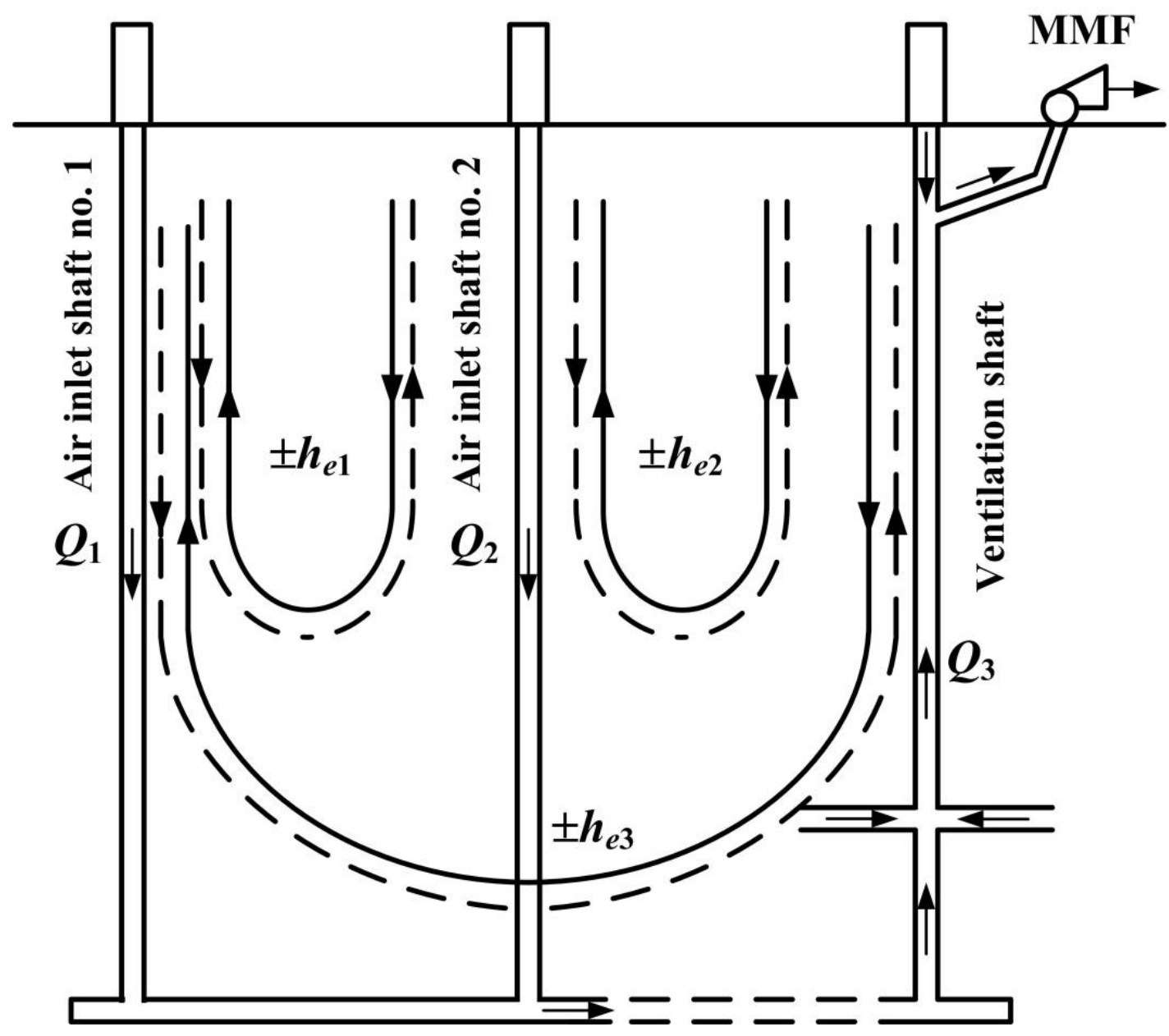

Fig. 2. Simplified schematic of ventilation of BKPRU-2 mine (with two air inlet shafts, exhaust system of ventilation)

\section{According}

to the paper [10], the value of the general mine natural draft is defined as an algebraic sum of all thermal drop values between shafts $h_{\mathrm{e}}=\sum_{i=1}^{n} h_{\mathrm{e}, i}$ (where $n$ is a quantity of the mine shafts) considering the difference of elevation marks of the shaft mouths.

As a result of the calculations it became clear that by the mine ventilation and after the MMF shutdown the negative general mine natural draft between the shafts was active which was directed opposite the air circulation through the shafts. Although due to that the MMF pressure was much higher than the arising draught, the air was supplied to the shafts in the required volume.

After the MMF shutdown, the fan-made pressure decreased and the general mine natural draft remained negative and almost did not change its value.

At some time $(22.20-22.40$ period $)$, a reverse of the air stream occurred, i.e. ventilation of the underground mining company started only due to the general mine natural draft after the full stop of the air circulation (the moment of the direction change). No additional draught sources were needed for that. 
TABLE I. Air parameters obtained as a result of the measurements in BKPRU-2 mine («Uralkali» PJSC)

\begin{tabular}{|c|c|c|c|c|c|c|c|c|c|c|c|c|}
\hline \multirow[t]{2}{*}{$\begin{array}{l}\text { № } \\
\mathrm{p} / \mathrm{p}\end{array}$} & \multirow{2}{*}{$\begin{array}{c}\text { Measure } \\
\text { ment } \\
\text { time }\end{array}$} & \multicolumn{2}{|c|}{ Outer air parameters } & \multicolumn{3}{|c|}{$\begin{array}{c}\text { Air parameters in } \\
\text { shaft № } 1\end{array}$} & \multicolumn{3}{|c|}{$\begin{array}{c}\text { Air parameters in } \\
\text { shaft № } 2\end{array}$} & \multicolumn{3}{|c|}{$\begin{array}{c}\text { Air parameters in } \\
\text { shaft № } 3\end{array}$} \\
\hline & & $t_{\mathrm{H}},{ }^{\circ} \mathrm{C}$ & $\begin{array}{l}P_{\mathrm{a}}, \text { mm of } \\
\text { mercury }\end{array}$ & $t_{1},{ }^{\circ} \mathrm{C}$ & $\begin{array}{c}P_{1}, \text { mm of } \\
\text { mercury }\end{array}$ & $Q_{1}, \mathrm{~m}^{3} / \mathrm{s}$ & $t_{2},{ }^{\circ} \mathrm{C}$ & $\begin{array}{c}P_{2}, \text { mm of } \\
\text { mercury }\end{array}$ & $Q_{2}, \mathrm{~m}^{3} / \mathrm{s}$ & $t_{3},{ }^{\circ} \mathrm{C}$ & $\begin{array}{c}P_{3}, \text { mm of } \\
\text { mercury }\end{array}$ & $Q_{3}, \mathrm{~m}^{3} / \mathrm{s}$ \\
\hline 1 & $22-00$ & 13.2 & 730.712 & 17.6 & 776.635 & 167.78 & 17.3 & 777.181 & 169.15 & 15.3 & 774.156 & 336.77 \\
\hline 2 & $22-20$ & 13.4 & 731.112 & 18.1 & 769.157 & 88.74 & 18.3 & 770.230 & 91.14 & 16.0 & 764.232 & 179.79 \\
\hline 4 & $23-20$ & 14.1 & 732.120 & 19.7 & 765.232 & -28.08 & 19.4 & 765.132 & 10.89 & 16.3 & 753.123 & -44.14 \\
\hline 5 & $23-40$ & 13.6 & 732.090 & 19.7 & 765.528 & -30.48 & 19.5 & 765.311 & -13.20 & 16.5 & 754.203 & -43.15 \\
\hline 6 & $00-20$ & 14.3 & 732.038 & 18.9 & 765.208 & -27.36 & 19.5 & 765.104 & -12.21 & 16.3 & 754.158 & -38.73 \\
\hline 7 & $00-40$ & 13.8 & 731.798 & 19.3 & 765.383 & -27.36 & 19.7 & 765.243 & -12.87 & 16.5 & 754.324 & -37.98 \\
\hline 8 & $01-20$ & 13.3 & 731.813 & 18.7 & 765.535 & -26.16 & 19.5 & 765.510 & -12.21 & 16.2 & 754.218 & -40.23 \\
\hline 10 & $02-10$ & 13.3 & 731.821 & 18.9 & 765.581 & -27.84 & 19.0 & 765.107 & -12.54 & 16.2 & 754.213 & -37.89 \\
\hline 11 & $02-40$ & 13.2 & 731.798 & 18.7 & 765.231 & -28.08 & 18.8 & 765.144 & -9.9 & 16.4 & 753.121 & -40.18 \\
\hline 12 & 03-00 & 13.1 & 731.760 & 18.7 & 765.357 & -27.84 & 19.1 & 765.223 & -11.22 & 16.2 & 754.212 & -41.35 \\
\hline 13 & $03-30$ & 13.4 & 731.655 & 18.9 & 765.325 & -29.76 & 18.7 & 765.217 & -11.22 & 16.1 & 754.209 & -43.36 \\
\hline 14 & 04-10 & 13.5 & 731.663 & 18.8 & 765.403 & -28.32 & 18.9 & 765.364 & -11.88 & 16.4 & 754.201 & -41.30 \\
\hline
\end{tabular}

There are formulas for determining the value of natural draft from the values of the average air densities in the shafts $[5,10]$.

1. For the air inlet shafts:

$\rho_{\text {a.i.s. }}=\frac{0.2325\left[P_{a}\left(546.3+2 t_{a}-X H_{\text {a.i.s. }}\right)-0.0075 R_{\text {a.i.s. }} Q_{\text {a.i.s. }}^{2}\left(273.15+t_{a}\right)\right]}{\left(273.15+t_{a}\right)\left[273.15+t_{a}+H_{\text {a.i.s. }}(X-0.01705)\right]}$

In formula (1), $P_{a}$ - atmosphere pressure, $\mathrm{mm}$ of mercury; $t_{a}$ - outside temperature, ${ }^{\circ} \mathrm{C} ; X$ - temperaturehumidity gradient [11]; $H_{\text {a.i.s. }}-$ depth of the air inlet shaft, m; $R_{\text {a.i.s. }}-$ aerodynamic drag of the air inlet shaft, $\left(\mathrm{N} \cdot \mathrm{s}^{2}\right) / \mathrm{m}^{8} ; Q_{a . i . s}$. - volume of air entering the air inlet shaft into the mine, $\mathrm{m}^{3} / \mathrm{s}$.

2. For the ventilation shaft:

$$
\begin{aligned}
& \rho_{v . s .}=\left[\frac{0.2325\left(273.15+t_{m}-H_{v . s .}(0.01705-Y)\right)}{273.15+t_{m}-Y H_{v . s .}}\right] \times \\
& {\left[\begin{array}{l}
\frac{\left(P_{a}+\left(0.0735 \rho_{\text {a.i.s. }} H_{v . s .}\right)-0.0075\left(\left(R_{\text {a.i.s. }}+R_{m}\right) Q_{m}^{2}\right)\right)}{273.15+t_{m}}+ \\
+\frac{\left(P_{a}+\left(0.0735 \rho_{\text {a.i.s. }} H_{v . s}\right)-0.0075\left(\left(R_{\text {a.i.s. }}+R_{m}+R_{v . s .}\right) Q_{m}^{2}\right)\right)}{273.15+t_{m}-Y H_{v . s .}}
\end{array}\right]}
\end{aligned}
$$

In formula (2), $t_{m}$ - air temperature at the outlet of the mine, ${ }^{\circ} \mathrm{C} ; H_{\text {v.s. }}$ - depth of the a ventilation shaft, $\mathrm{m} ; Y-$ temperature-humidity gradient [11]; $R_{m}$ - aerodynamic drag of the underground part of the mine, $\left(\mathrm{N} \cdot \mathrm{s}^{2}\right) / \mathrm{m}^{8} ; R_{v . s .}-$ aerodynamic drag of the ventilation shaft, $\left(\mathrm{N} \cdot \mathrm{s}^{2}\right) / \mathrm{m}^{8} ; Q_{m}-$ air volume at the outlet of the mine, $\mathrm{m}^{3} / \mathrm{s}$.

The natural thrust acting between the two shafts is determined by the hydrostatic method of calculation:

$$
h_{e(i, j)}=9.81 H\left(\rho_{i}-\rho_{j}\right), \mathrm{Pa},
$$

In formula (3), $H$ - depth of air column in the shafts, m. After the mean air densities in the shafts have been determined, the natural draft values between each pair of trunks are found from formula (3).

The calculation of the natural draft must take into account the mutual alignment of air shafts; the difference of altitude marks between shafts collars is particularly influential: as the natural draft can only arise between the communicating shafts. Therefore, the total height of air columns in the communicating shafts should be included in the calculations of the natural draft. For example, if the collar of the air inlet shaft $a b$ locates lower than the collar of the ventilation shaft $\mathrm{cd}$ (Figure 3), the average density of the total air column is calculated as:

$$
\rho_{\text {column }}=\frac{\rho_{a b} H_{1}+\rho_{\text {fresh }} \Delta H}{H_{2}} .
$$

Thus, in the warm season, the total air column density $\rho_{\text {column }}$ is lower than in the cold season. No doubt, in terms of (3), this fact will affect the value of the natural inter-shafts draft. The higher the difference of the altitude marks of shaft collars $(\Delta H)$, the greater the influence.

Thus, the calculation is the need to study the influence of mutual alignment of shaft collars on the thermal drop of ventilation pressure between the shafts, and on the natural draft across the mine.

For the calculation, one can use a substitution scheme (Figure 4).

Volume air flow measured in real conditions differs from the calculations results (according to the mathematical 
relations of the paper [11]) within 2-3\%. Besides, it has been established that the general mine natural draft actually equals the algebraic sum of thermal drop between the shafts.

2. Thermal drop between the shafts is continuous regardless of the ventilation mode. Only two factors have an impact on the pressure value - the difference of temperature and pressure of the outer air and the air in the shaft bottoms.

Such conclusion has been made on the basis that the values of thermal drop between the shafts and, accordingly, the values of the general mine natural draft were almost stable by operating MMF, after the stop of the forced ventilation and for several hours. It could be caused by a small change of the outer air parameters. If one compares the air pressure value in the shaft bottoms by the MMF operation and after its shutdown, one can see that the parameters difference is quite considerable. Although the difference between the values in the shafts was almost stable. Thus, the MMF operation mode has almost no impact on the value of the general mine natural draft. On that basis, it can be supposed that the air pressure and temperature in the shaft bottoms will increase by changing the shaft depth and the difference of these values are not to change considerably. In this case, it can be said that the shaft depth is also not a parameter, which influences the value of the general mine natural draft by ventilation of the underground mining company.

3. The single case of absence of the general mine natural draft between the shafts is location of all the shaft mouths on the same elevation mark on surface and location of the shaft low points (shaft bottoms) at the same level.

Such situation in real conditions is almost impossible, consequently the general mine natural draft between the shafts will be always active. Another issue is that its value can be neglected by low elevation differences.

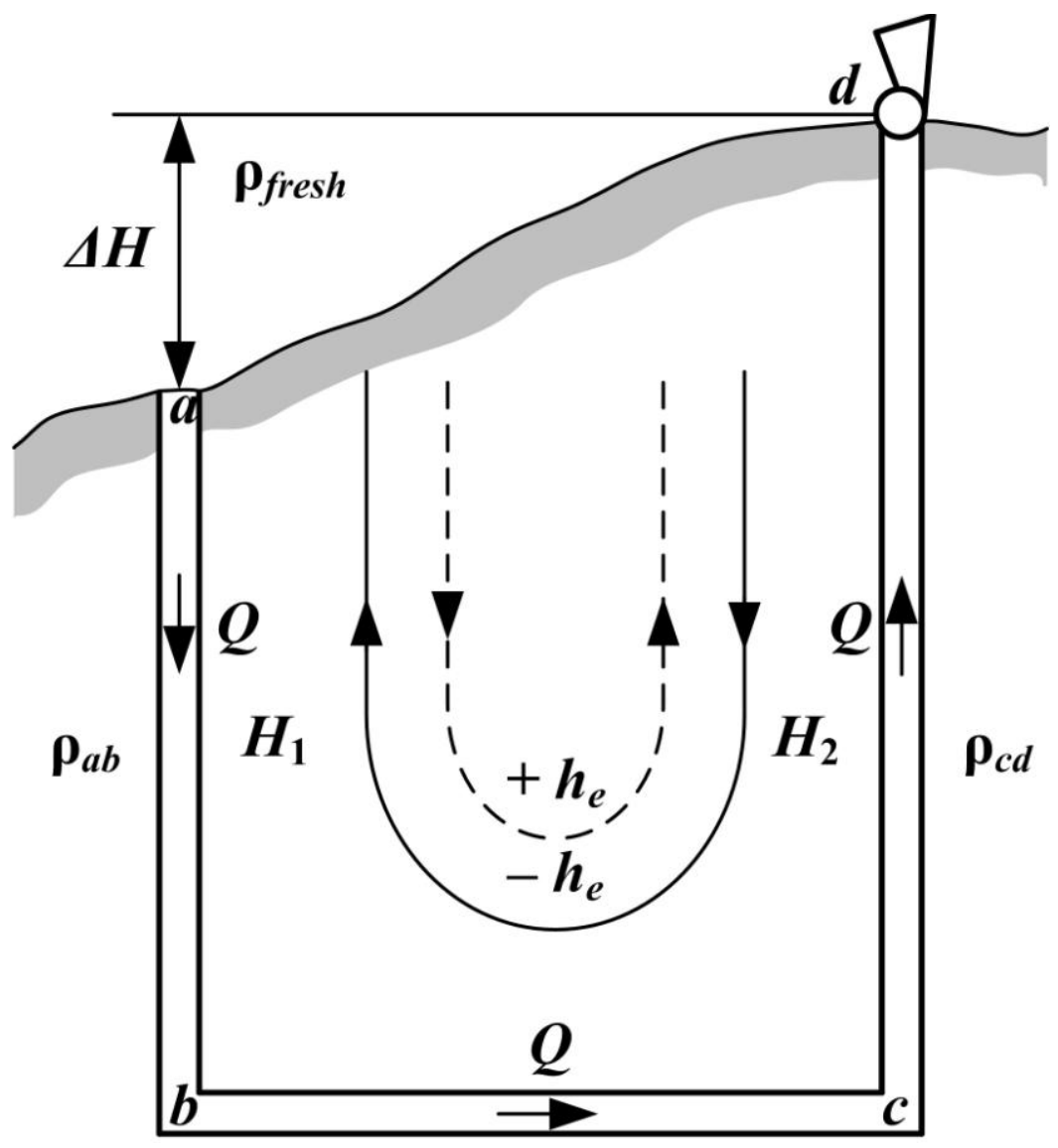

Fig. 3. Natural draft between shafts with collars located at different altitude marks

In this case, the value of the general mine

natural draft will rise if there are more differences between the outer air parameters and the parameters on the mine stratum depth. 


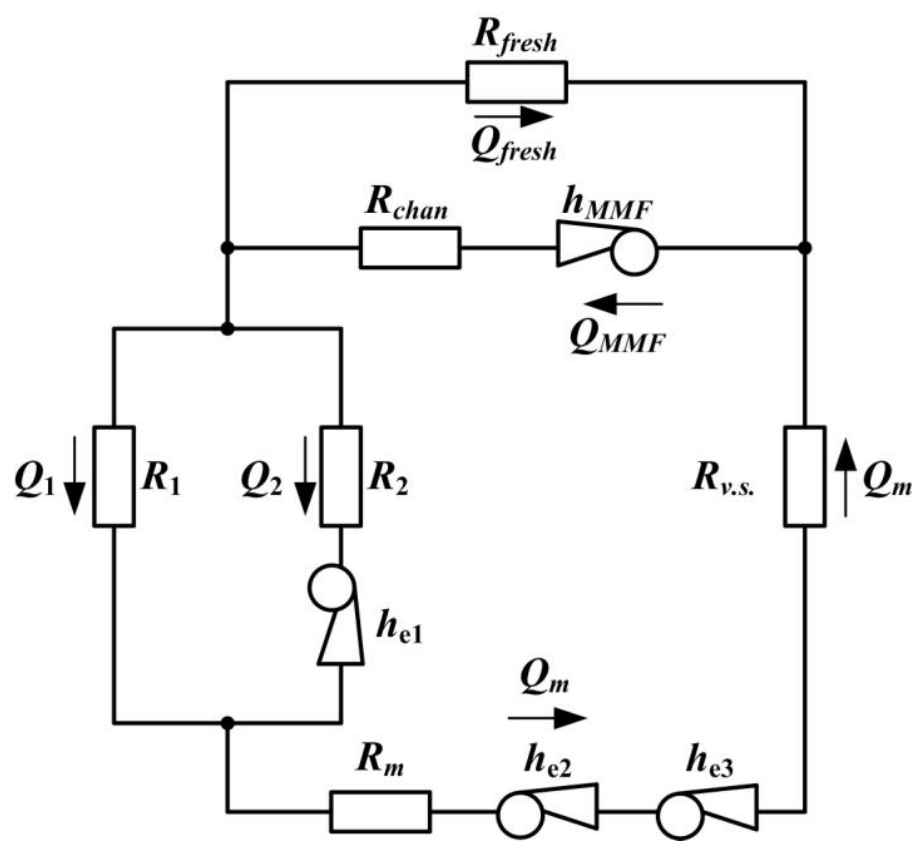

a)

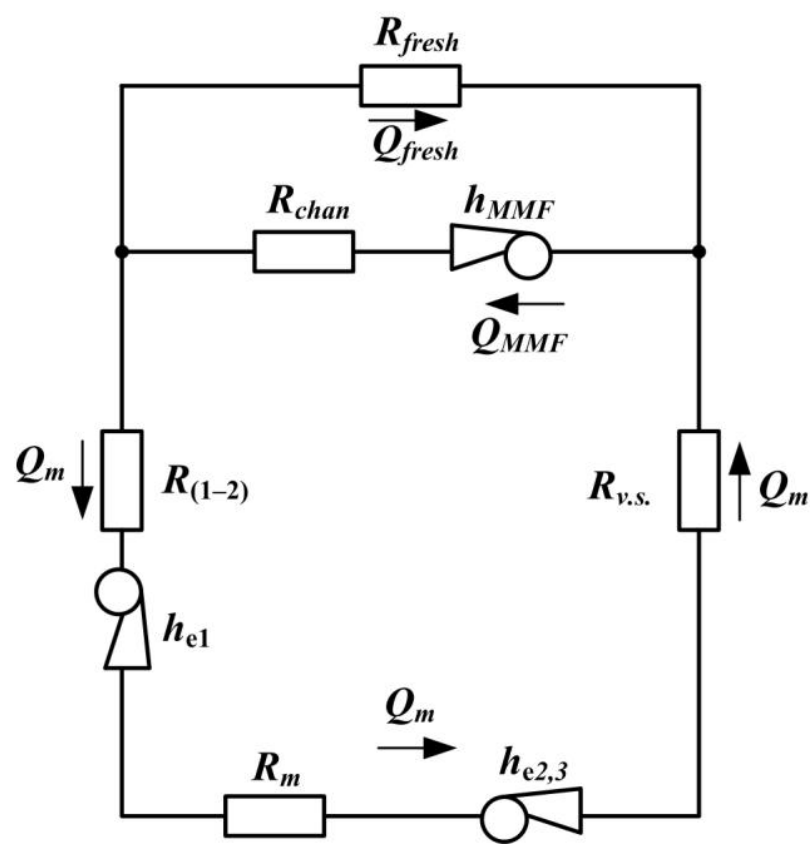

b)

Fig. 4. The mine calculation schemes : $R_{1}, R_{2}, R_{\text {chan }}, R_{\text {fresh }}, \mathrm{R}_{(1-2)}$, are, respectively, the air drags in air inlet shafts nos. 1 and 2 in the mine, MMF channel, in the fresh air and in the communicating air inlet shafts; $Q_{1}, Q_{2}, Q_{f r e s h}$, are, respectively, air flows in air inlet shafts nos. 1 and 2 , and the fresh air flow; $Q_{M M F}, h_{M M F}$, are the MMF capacity and pressure

\section{CONCLUSION}

Due to the fact that the general mine natural draft has a strong effect on the MMF operation in some cases, it is necessary to consider the draught action by the ventilation process. Based on the performed experimental research, it has been found that the general mine natural draft is active between the mine shafts continuously, and its value depends on the outer air parameters and the air parameters in the shaft bottoms. Thermal pressure equal by the value and direction will be active between the shafts of the same mine by the same specified air parameters regardless of the MMF operation mode. However, it is necessary to take into account that such a situation will arise only by pthe ower-off air handling system (unit-heaters, air conditioning systems).

\section{References}

[1] W.E. Bruce, Natural draft: its measurement and modeling in underground mine ventilation systems, 1986, pp. 12-28.

[2] P.F. Linden, "The fluid mechanics of natural ventilation," Annual Review of Fluid Mechanics, vol. 31, pp. 201-238, 1999.

[3] J. Cheng, Y. Wu, H. Xu, J. Liu, Y. Yang, H. Deng, Y. Wang, "Comprehensive and integrated mine ventilation consultation model," Tunneling and Underground Space Technology, vol. 45, pp.166-180, 2015.

[4] S. G. Gendler, "The justification of new technique ventilation at contraction of working with two exits in soil surface," Eurasian Mining, vol. 2, pp. 41-44, 2016.

[5] G.B. Lyal'kina, A.V. Nikolaev, "Natural draught and its direction in a mine at the preset confidence coefficient," Journal of Mining Science, vol. 51(2), pp. 342-346, 2015.

[6] A.V. Krainov, E.N. Pashkov, A.V. Ponomaryov, "Conjugate heat transfer in the interaction of the viscous liquid with technological
Thus, the value of thermal drop which will be active between the shafts, can be defined for each certain mine using the outer air parameters and the air parameters in the shaft bottoms. Having defined the value of the general mine natural draft as an algebraic sum of thermal drop between the shafts, it is possible to provide the MMF operation when the underground mining company is supplied with the required air volume by minimum power costs for ventilation. Thanks to similar research for the mines by operation of the air handling systems, the power saving mode of ventilation can be set up due to the change of the MMF operation mode considering the effect of the general mine natural draft year-round.

elements of energy systems in conditions of their internal contour moving," Advanced Materials Research, vol. 1040, pp. 876-880, 2014.

[7] B.P. Kazakov, A.V. Shalimov, E.L. Grishin, “Two-layer approximated approach to heat exchange between the feed air and ventilation shaft lining," Journal of Mining Science, vol. 47(5), pp. 643-650, 2011.

[8] B.P. Kazakov, A.V. Shalimov, M.A. Semin, "Stability of natural ventilation mode after main fan stoppage," International Journal of Heat and Mass Transfer, vol. 86, pp. 288-293, 2015.

[9] V.N. Karelin, A.V. Kravchenko, B.P. Kazakov, A.V. Zaitsev, "Features of forming microclimatic conditions in mining excavations of deep mines," Gornyi Zhurnal, vol. 6, pp. 65-68, 2013.

[10] N.N. Mohirev, V.V. Rad'ko, Engineering calculations of ventilation of mines, 2007, $324 \mathrm{p}$.

[11] N.I. Alymenko, A.A. Kamenskikh, A.V. Nikolaev, A.I. Petrov "Numerical modeling of heat and mass transfer during hot and cool air mixing in air supply shaft in underground mine," Eurasian mining, vol. 2 , pp. $45-47,2016$. 